\title{
DIURNAL VARIATION OF CARBON DIOXIDE FLUX ABOVE GROWING COWPEA (VIGNA UNGUICULATA [L.] WALP) AT AN AGRICULTURAL SITE IN ILE-IFE, NIGERIA
}

\author{
Ajao, A. I. * and Jegede O. O. \\ Department of Physics and Engineering Physics, Obafemi Awolowo University, Ile-Ife, Nigeria. \\ *Correspondence: Adewale Ajao (iyiolamercy2005@yahoo.com or a.ajao@oauife.edu.ng) \\ (Received: $5^{\text {th }}$ December, 2018; Accepted: 21 ${ }^{\text {st }}$ May, 2019)
}

ABSTRACT

\begin{abstract}
The goal of this study was to investigate the diurnal variation of carbon dioxide $\left(\mathrm{CO}_{2}\right)$ flux above cowpea (Vigna unguiculata [L.] Walp) in relation to its phenological stages of growth. The experimental site was an agricultural area located at the Teaching and Research farm of Obafemi Awolowo University, Ile-Ife, Nigeria.. The planting of cowpea covered two cycles, March-June and August-November, 2015, which represented dryto-wet and wet-to-dry seasonal transitions in the area respectively. An eddy covariance system was deployed on site from which turbulent flux of carbon dioxide had been determined. In addition, net radiation, photosynthetically active radiation (PAR), leaf surface temperature, soil moisture and thermal parameters were measured within the plant environment. Concentration of $\mathrm{CO}_{2}$ at the study location decreased by about $50 \%$ to minimum values, $650 \mathrm{mgm}^{-3}$ at $1500 \mathrm{hrs}$ (LT), which is coincident with maximum PAR value of $1800 \mathrm{Wm}^{-2}$. From sunset until dawn, the $\mathrm{CO}_{2}$ flux measured increased steadily from about $0.2 \mathrm{mgm}^{-2} \mathrm{~s}^{-1}$ around $1800 \mathrm{hrs}$ (LT) to reach maximum value, about $0.5 \mathrm{mgm}^{-2} \mathrm{~s}^{-1}$ at $0300 \mathrm{hr}$. Irrespective of growth stage of the plant, $\mathrm{CO}_{2}$ flux was maximum during nighttime.
\end{abstract}

Keywords: Cycles, Phenological stages, Plant environment, Seasonal transitions, Turbulent flux

\section{INTRODUCTION}

Concentrations of atmospheric carbon dioxide $\left(\mathrm{CO}_{2}\right)$ are reported to be on the increase since the beginning of the industrial era, and projections have been made that these concentrations would have risen to about $500 \mathrm{ppm}$ or more by 2100 (IPCC 2007; Taub, 2010; EPA 2015). Moreover, the percentage increase of carbon in the atmosphere which is exchanged with the terrestrial environment has been approximated to be about $14 \%$ annually. It is therefore evident that different terrestrial surfaces contribute to regional carbon budgets in different ways mainly due to the heterogeneity of the ecosystems (Zhang et al., 2015; Baldocchi et al., 2001; Zhao et al., 2010). Although, the observed increase has been noticed to have serious effects on global climate, attentions must rather be drawn to the effects such rise in concentrations will have on the terrestrialbiosphere system (Ziska, 2008; Zhang et al., 2015).

The survival of any plant in a terrestrial environment depends on the amount (fraction) of solar radiation available for such plant to undergo photosynthesis. This fraction of the solar radiation is referred to as photosynthetically active radiation (PAR). PAR together with other essential environmental variables such as carbon dioxide $\left(\mathrm{CO}_{2}\right)$, water vapor etc., are necessary for proper growth and development of plants. As plants photosynthesize, they take up atmospheric $\mathrm{CO}_{2}$, chemically reducing the carbon, leading to acquisition of stored chemical energy in them. The common elements (i.e. carbon, hydrogen and oxygen) injected into organic molecules by photosynthesis make approximately $96 \%$ of the total dry mass of a typical plant. Photosynthesis is therefore said to be at the heart of nutritional metabolism of plants (Taub, 2010; Gilmanov et al., 2014; Neumann et al., 2015). However, increasing the availability of $\mathrm{CO}_{2}$ for photosynthesis can have serious effects on the growth of plant and its physiology (Loladze, 2002; Keeling et al., 2005; Vanuytrecht et al., 2011). As $\mathrm{CO}_{2}$ concentrations increase, plants should maintain high photosynthetic rates with low stomata conductance for low rates of water loss. As a matter of fact, it is expedient that measurements of $\mathrm{CO}_{2}$ quantifying the variation of carbon flux over plants be taken, to estimate its concentration for daytime and nighttime 
conditions, so as to be able to check for any serious effects that might need to be reported and corrected as plants continue to use it (Phillips et al., 1998; Casso-Torralba et al., 2008).

The primary objective of this study is to investigate the diurnal variation of $\mathrm{CO}_{2}$ flux over a leguminous plant (cowpea) using eddy covariance (EC) technique. The method is currently the most accurate, reliable and non-destructive approach for measuring turbulent fluxes of $\mathrm{CO}_{2}$ in an ecosystem (Zhang et al., 2015; Dragomir et al., 2011). Other objectives are to quantify $\mathrm{CO}_{2}$ fluxes for different growth and developmental stages of the plant for two transitional planting seasons, and identify the major factor(s) responsible for the regulation of the fluxes at the study site.

\section{METHODOLOGY}

\section{Site description}

The experimental site for this study was located at Teaching and Research Farm of Obafemi Awolowo University campus in Ile-Ife, Nigeria $\left(7.52{ }^{\circ} \mathrm{N} ; 4.52{ }^{\circ} \mathrm{E} ; 296 \mathrm{~m}\right)$ as shown in the Fig. 1. The selection of the site for the purpose of this study was due to its open and level terrain nature. This is to meet the steady-state and stationarity conditions required to achieve accuracy in measurement. It is located in a low wind area and about $7 \mathrm{~km}$ north-east of the main campus. The mean wind speed at the study site is less than 1.5 $\mathrm{ms}^{-1}$ (Jegede et al., 1997; Ayoola et al., 2014). It has a dimension approximated $1500 \mathrm{~m}$ by $300 \mathrm{~m}$. Typical varieties of arable crops; such as maize, cassava, water melon and fruits are planted every year and the area is characterized with a few scattered trees. The soil type is loamy-clay from the top to the bottom. There are offices and facility buildings for the use of staff members available at the site and lecture rooms for 400 level students in their farm year. Units such as poultry, piggery and cattle are also represented within the farm center. The study area which is approximated $60 \mathrm{~m}$ by $45 \mathrm{~m}$ was planted with cowpea. Cowpea was chosen for the purpose of its homogeneous nature in growth and ability to fix nitrogen by its root nodules. This was done to meet the homogeneity condition as required for the accuracy of eddy covariance technique being employed in this study.

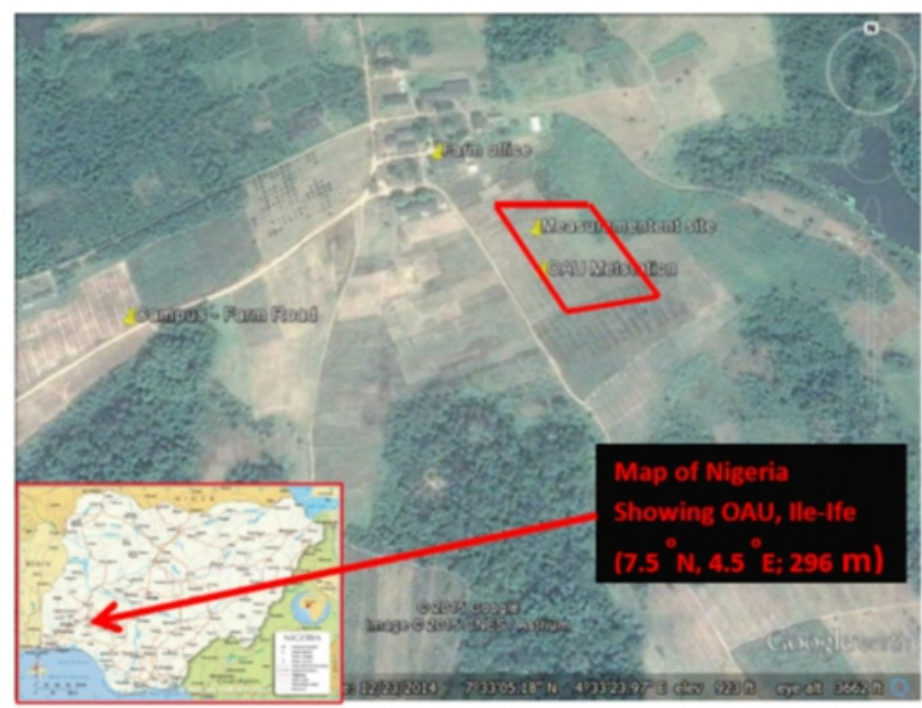

Figure 1: Plan view of study site at the T \& R Farm, ObafemiAwolowo University, Ile-Ife, Nigeria. Insert is map of Nigeria showing OAU campus (googleearth.com, 2015).

\section{Measurements, Data acquisition and Processing}

Three separate short masts $(1.5 \mathrm{~m}, 1.6 \mathrm{~m}$ and 2.2 $\mathrm{m}$ tall) were installed at the experimental site as shown in the Fig. 2. The eddy covariance (EC) system comprised an ultrasonic anemometer (model CSAT3, Campbell Scientific. Inc. USA) and an infrared gas analyzer (model LI 7500, LiCOR Inc. USA). These were mounted at $2.0 \mathrm{~m}$ above ground level on a $2.2 \mathrm{~m}$ tall mast and turbulent fluxes of carbon dioxide $\left(\mathrm{CO}_{2}\right)$ were sampled and stored. Wind speed was measured 


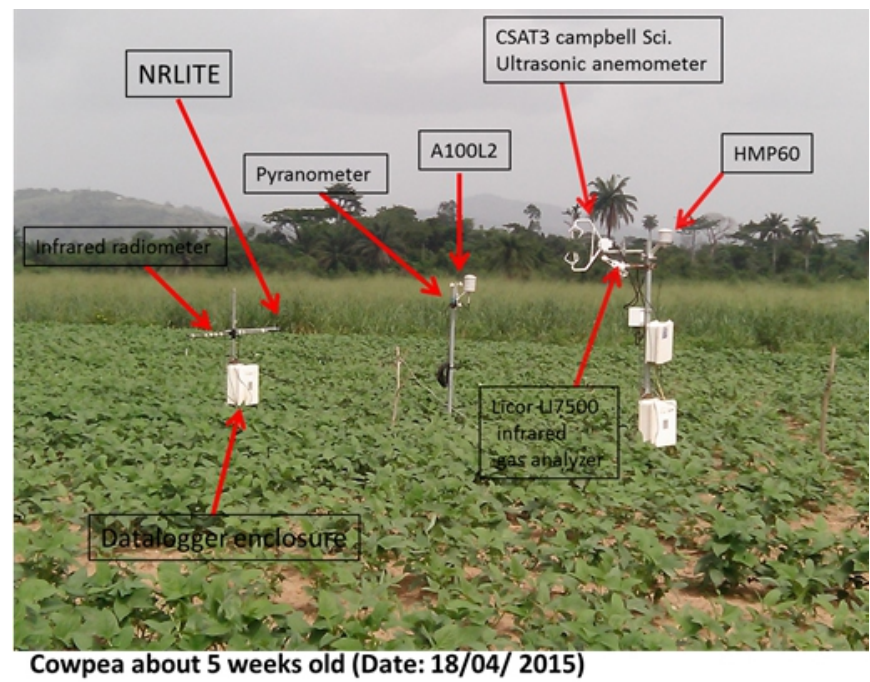

along the three orthogonal dimensions by CSAT3 while $\mathrm{CO}_{2}$ flux and water vapor density were sampled by LI 7500 infrared gas analyzer (see Campbell Scientific Instruments manual, 2010). The HMP60 recorded the air temperature and relative humidity. Positioning of the EC system in the planted area (middle of the study area) was such that the placement of fast response sensors (CSAT3 and LI 7500) at $2.0 \mathrm{~m}$ above the surface was in the ratio 100:1 with reference to the area fetch. This is to ensure that the system captured data (surface flow) from every angle to satisfy the fetch and stationarity conditions requirements. On the $1.6 \mathrm{~m}$ mast were mounted slow response sensors; cup anemometer (A100L2), pyranometer (Kipp \& Zonen) and HMP45C, all at the same level at a height of $1.5 \mathrm{~m}$ above the surface. A precision infrared radiometer (SI-111) for leaf surface temperature, net radiometer (NR-Lite) for net radiation and LICOR quantum sensor (LI190SB) for PAR, were integrated for measurements at height $1.45 \mathrm{~m}$ on the $1.5 \mathrm{~m}$ mast. The turbulent parameters were sampled at $10 \mathrm{~Hz}$ and averaged at $30 \mathrm{~min}$. interval. They were stored by a CR1000 datalogger and later downloaded on a PC (HP-laptop). The meteorological variables; mean wind speed, solar radiation, air and soil temperatures, soil moisture, relative humidity, soil heat flux, leaf surface temperature and PAR were also sampled at $10 \mathrm{~s}$ and averaged at 2 mins interval. After subjection to various tests and careful elimination of spurious flux data values from the datasets using quality control and quality assurance (QA/QC) protocol, stationarity test was performed following the procedure given by Foken and Wichura (1996). The datasets were then reduced to 30 minutes averages and used for further analysis.

\section{RESULTS AND DISCUSSION Diurnal Variation of $\mathrm{CO}_{2}$ Concentration and Photosynthetically Active Radiation (PAR)}

The diurnal variations of concentration and turbulent flux of carbon dioxide $\left(\mathrm{CO}_{2}\right)$ and Photosynthetically Active Radiation (PAR) for different developmental stages of cowpea for the transitions, dry-to-wet and wet-to-dry are shown in the Figs. 3 to 6. In the Fig. 3(a), for phase 1 of the measurement, dry-to-wet transition (March June), the concentration of $\mathrm{CO}_{2}$ as observed for emergence was $800.0 \mathrm{mgm}^{-3}$ at about $0300 \mathrm{hr}$ before sunrise. The rise in concentration is adduced mainly to soil and plant respiration. The high nighttime value of $\mathrm{CO}_{2}$ flux dropped to about $650.0 \mathrm{mgm}^{-3}$ at about $1500 \mathrm{hr}$ of the same day. The drop is attributable to photosynthetic activity during the daytime. In the vegetative stage of its growth as shown in the Fig. 3(b), the value of $\mathrm{CO}_{2}$ concentration observed was less than that observed for emergence. The difference in the values is attributable to the rate of soil and plant respiration being less in the vegetative stage, and photosynthesis being higher than in the emergence stage. Similarly, in the Fig. 4(a), wet-todry transition (August - November), $\mathrm{CO}_{2}$ 
Ajao and Jegede: Diurnal Variation of Carbon Dioxide Flux

concentration varied between $650 \mathrm{mgm}^{-3}$ and $720.0 \mathrm{mgm}^{-3}$. These values were close to the values observed in the first transition. In a like manner, there was a drop in the $\mathrm{CO}_{2}$ concentration in the vegetative stage of the plant due to similar reason earlier stated. For both transitions, variations in the concentrations of $\mathrm{CO}_{2}$ for flowering, maturity and senescence stages were similar. High values of $\mathrm{CO}_{2}$ concentrations were observed for nighttime periods (stable conditions) while low values were observed for daytime periods (unstable conditions) due to similar reasons earlier stated.
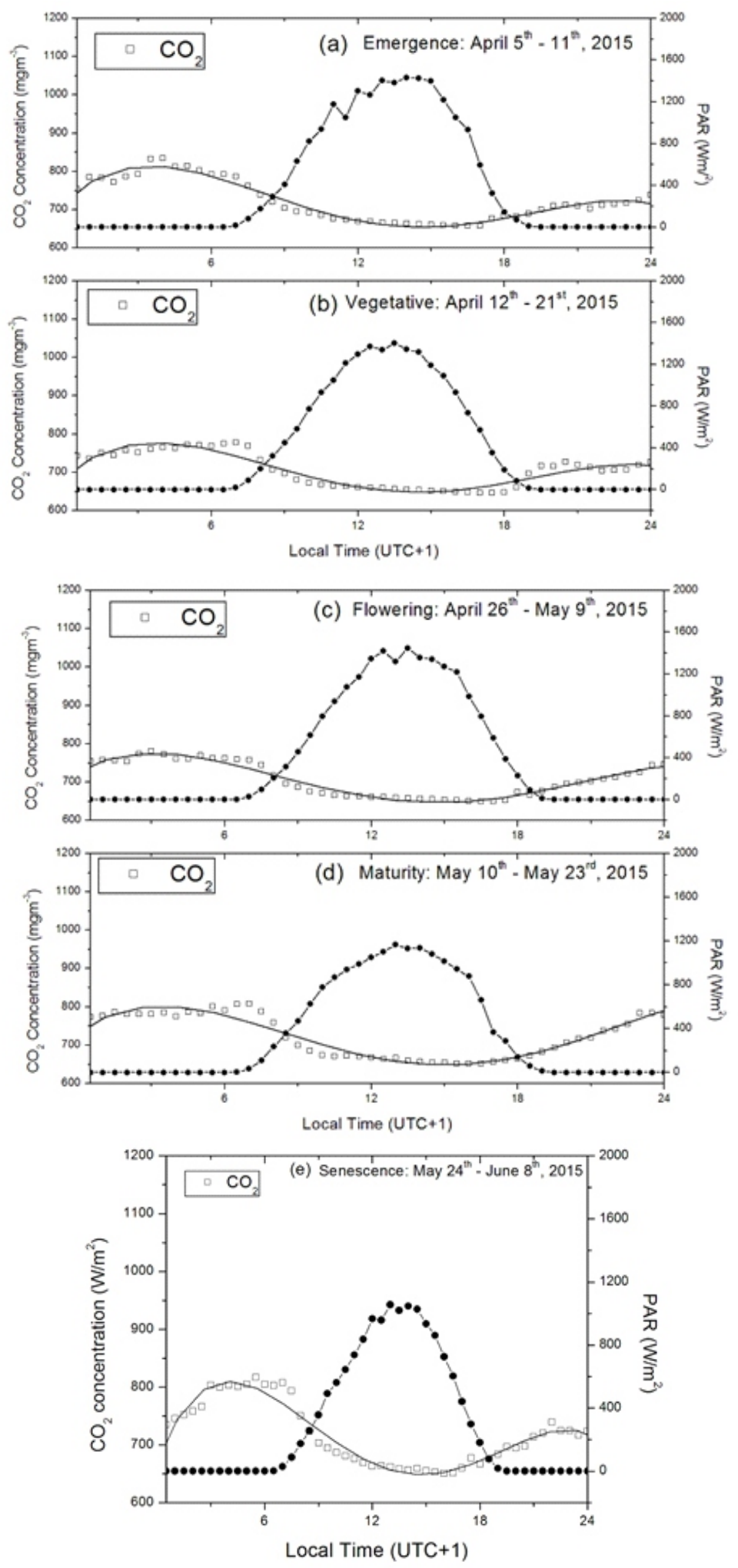

Figure 3: Diurnal variation of $\mathrm{CO}_{2}$ Concentration and PAR above cowpea at $\mathrm{T} \& \mathrm{R}$ Farm, OAU, Ile-Ife $\mathrm{d} \mathrm{u} \mathrm{ring}$ i t s developmental stages (Phase I: April - June, 2015). 

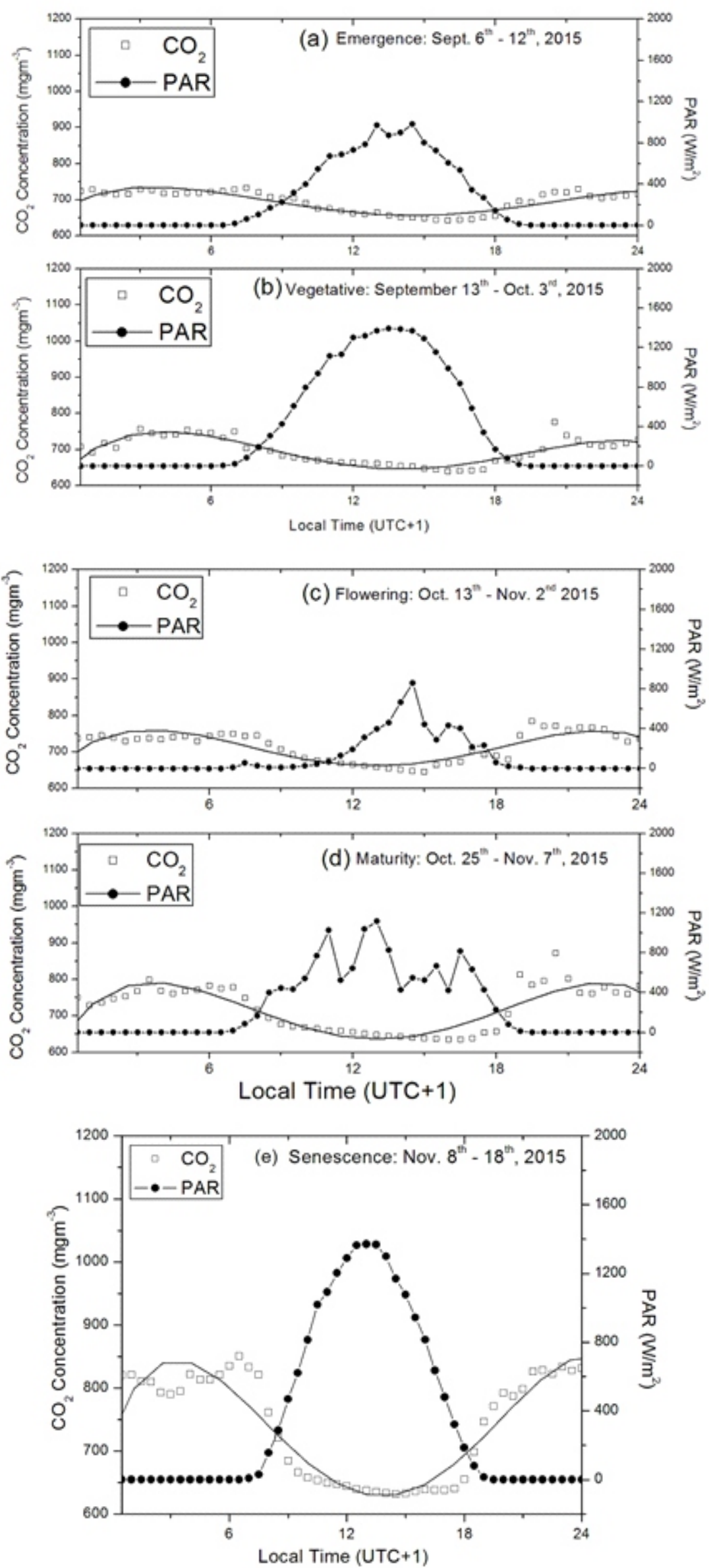

Figure 4: Diurnal variation of $\mathrm{CO}_{2}$ Concentration and PAR above cowpea at $T \& R$ Farm, OAU, Ile-Ife d u r i n g i t s developmental stages (Phase 2: $\mathrm{S}$ e p t e m b e r November 2015). 
Ajao and Jegede: Diurnal Variation of Carbon Dioxide Flux
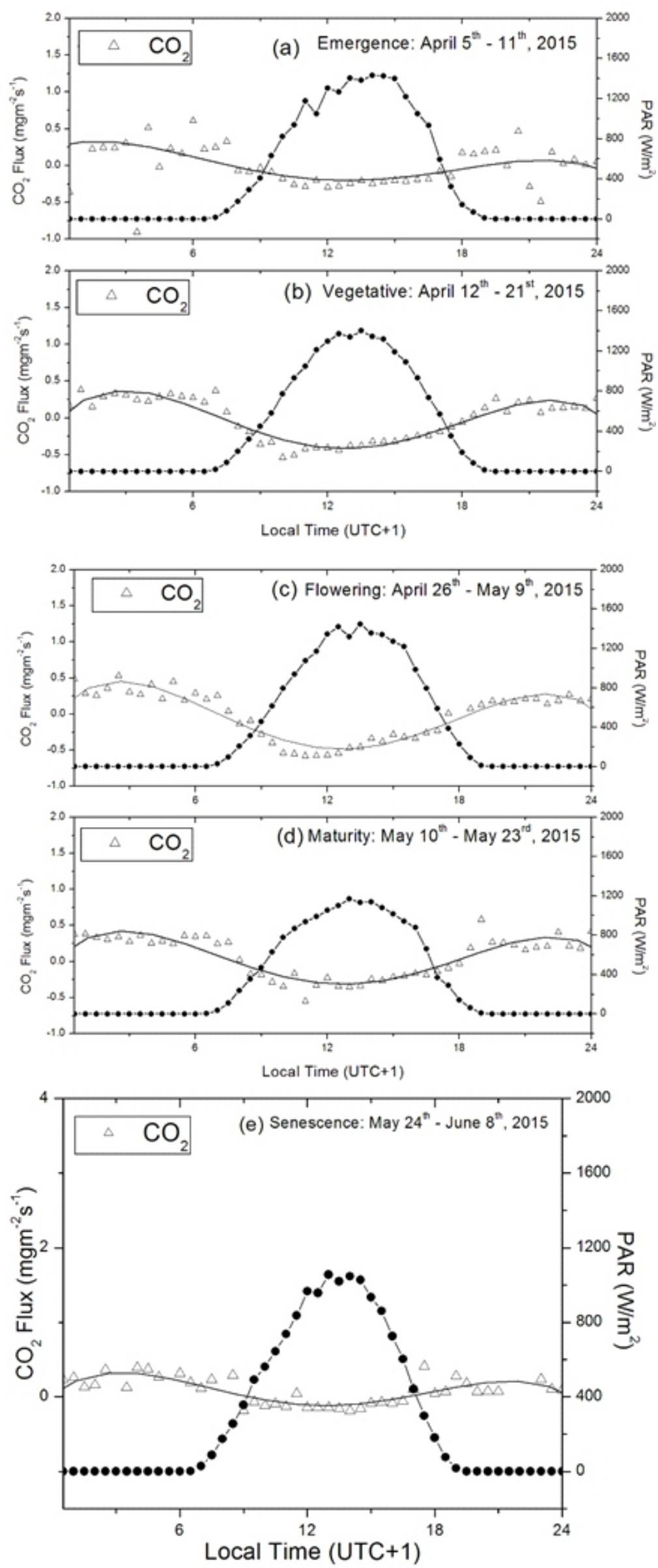

Figure 5: Diurnal variation of $\mathrm{CO}_{2}$ Fluxes and PAR above cowpea at T \& R Farm, OAU, Ile-Ife during its developmental stages (Phase I: April - June 2015). 

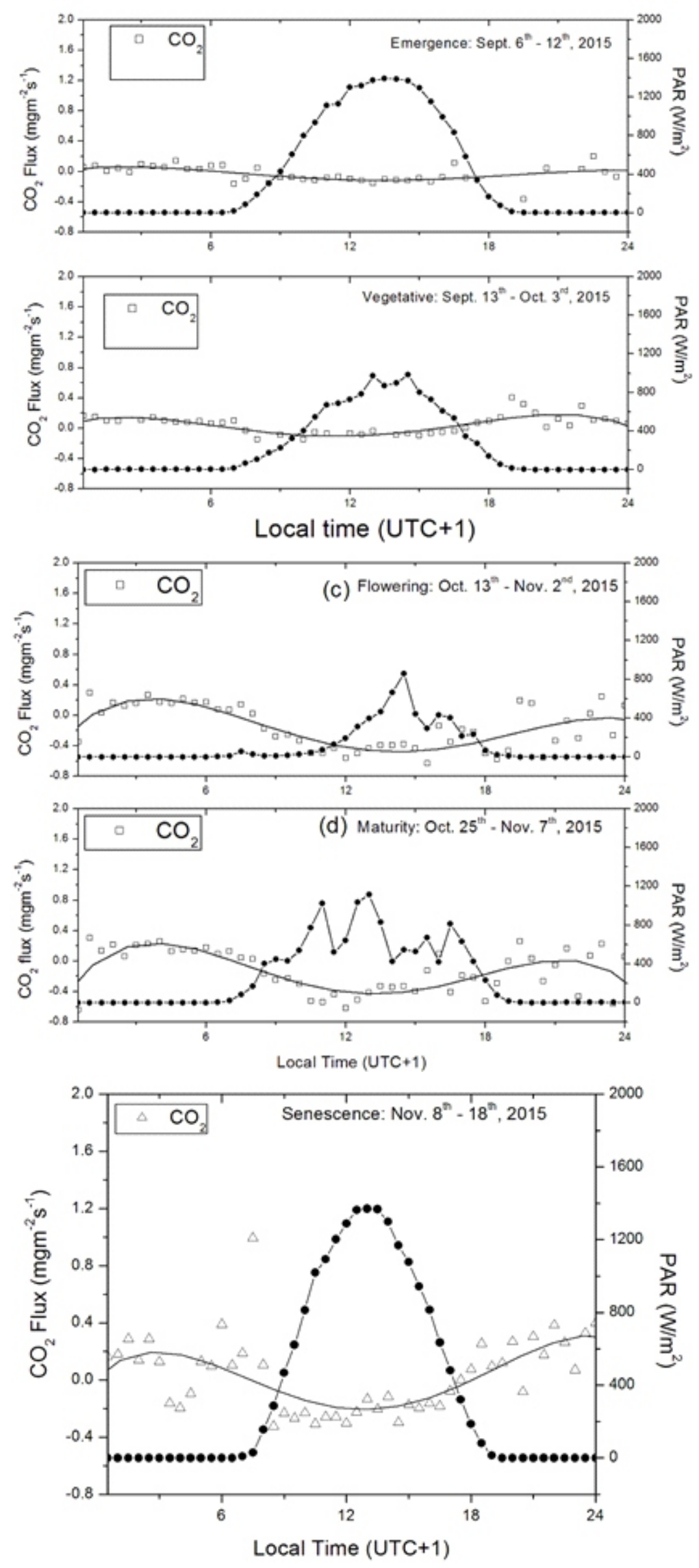

Figure 6: Diurnal variation of $\mathrm{CO}_{2}$ Fluxes and PAR above cowpea at $\mathrm{T} \&$ R Farm, OAU, Ile-Ife $\mathrm{d} \mathrm{u} \mathrm{ring} \mathrm{i} \mathrm{t} \mathrm{s}$ developmental stages (Phase 2: SeptemberNovember, 2015). 
Figure 5 shows the diurnal variation of $\mathrm{CO}_{2}$ flux with PAR during the developmental stages of cowpea. The fluxes varied in values between -0.5 and $0.5 \mathrm{mgm}^{-2} \mathrm{~s}^{-1}$ for all the developmental stages. The values of $\mathrm{CO}_{2}$ flux gradually dropped from sunrise at about $0600 \mathrm{hr}$. to sunset around $1800 \mathrm{hr}$ with increased PAR values. The flux increased with PAR value less than $500.0 \mathrm{Wm}^{-2}$. As PAR value rose to about $1000 \mathrm{Wm}^{-2}$, there was a drop in the $\mathrm{CO}_{2}$ flux, largely due to its use for photosynthesis resulting in a net assimilation of $\mathrm{CO}_{2}$. During the emergence, when the plant had not really grown shoots, the $\mathrm{CO}_{2}$ fluxes were almost constant in values, even in the daytime due to the absence of photosynthesis. For vegetative, flowering and maturity, the dips observed from about $0900 \mathrm{hr}$ to about $1800 \mathrm{hr}$ were attributable to prominent and vigorous photosynthesis at the surface. Similarly, in the Fig. 6, $\mathrm{CO}_{2}$ flux was noticed to be constant in value with PAR in the emergence stage of plant growth while it ranged from about - 0.3 to $0.3 \mathrm{mgm}^{-2} \mathrm{~s}^{-1}$ for other growth stages mentioned above. The drop in the range of values of $\mathrm{CO}_{2}$ flux for wet condition as stated above was attributable to increase in soil and plant moisture content during this period as compared to the dry condition.

\section{Diurnal Variation of $\mathrm{CO}_{2}$ Flux and Meteorological Variables}

The diurnal variations of the concentration and flux of $\mathrm{CO}_{2}$ have been determined alongside some meteorological variables as shown in the Figs. 7 and 8 for phases 1 and 2 of the measurements. In the Fig. 7, May $28^{\text {th }} 2015$, being representative data for dry-to-wet transition, each plot in the panels showed the signatures of concentration and flux of $\mathrm{CO}_{2}$ and other variables. The highest positive $\mathrm{CO}_{2}$ fluxes were observed in the nighttime. This is largely attributed to the release of $\mathrm{CO}_{2}$ to the atmosphere via respiratory processes from the soil and plant at the site. However, photosynthesis is completely absent at nighttime which then made the $\mathrm{CO}_{2}$ flux values to be positive. Common to all the plots is the drop observed in the values (magnitudes) of $\mathrm{CO}_{2}$ concentration and flux with increased values of the meteorological variables in the daytime. For example, increase in the value of net radiation leads to a drop in the concentration and flux of $\mathrm{CO}_{2}$ in the daytime, while the reverse is the case for nighttime conditions (see Figs. 7 (a) and (c)). The case is similar for global radiation as shown in the Figs. 7 (b) and (d). The soil temperature and soil heat flux showed diurnal variation with $\mathrm{CO}_{2}$ flux with highest positive and lowest negative fluxes observed during nighttime and daytime respectively (see Figs. $7(\mathrm{e})$ and (f)). In the Figs. 8(a) - (f), October $20^{\text {th }}, 2015$, being representative data for wet-to-dry transition, the meteorological variables showed significant variations with $\mathrm{CO}_{2}$ concentration and flux and the results obtained are very similar to those in the Fig. 7 above. Notably, for May $28^{\text {th }}, 2015$, the net and global radiation values, $650 \mathrm{Wm}^{-2}$ and 750 $\mathrm{Wm}^{-2}$ were higher than $380 \mathrm{Wm}^{-2}$ and $520 \mathrm{Wm}^{-2}$ as observed for October $20^{\text {th }}, 2015$. The higher values observed for the former date could be attributed to increase in the amount of solar insolation at the surface. There is also a drop in soil temperature by about $8^{\circ} \mathrm{C}$ and soil heat flux by about $10 \mathrm{Wm}^{-2}$. 
Ajao and Jegede: Diurnal Variation of Carbon Dioxide Flux
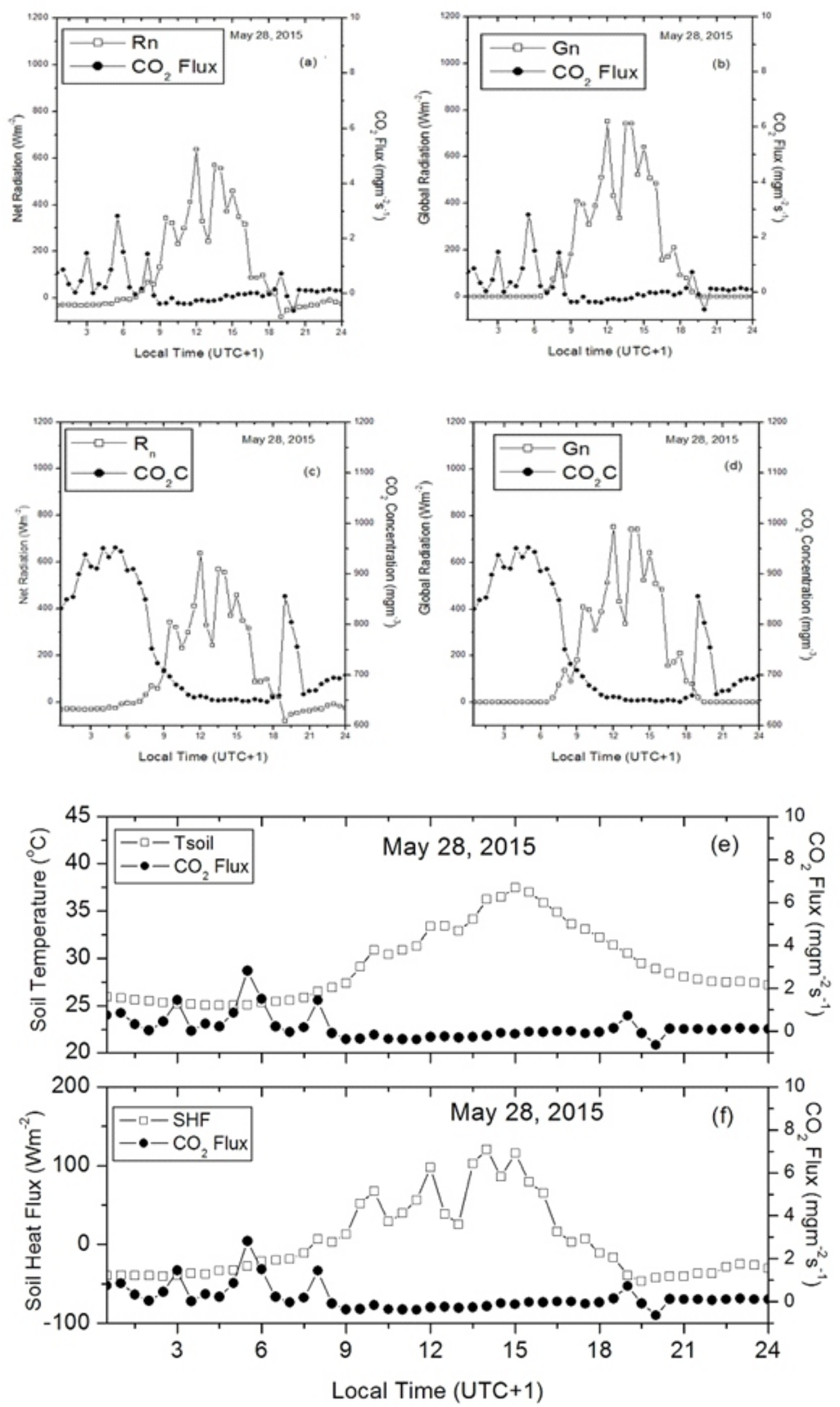

Figure 7: Diurnal Variation of $\mathrm{CO}_{2}$ Concentration and Fluxes and meteorological variables (Phase I: May 2015). 
Ajao and Jegede: Diurnal Variation of Carbon Dioxide Flux
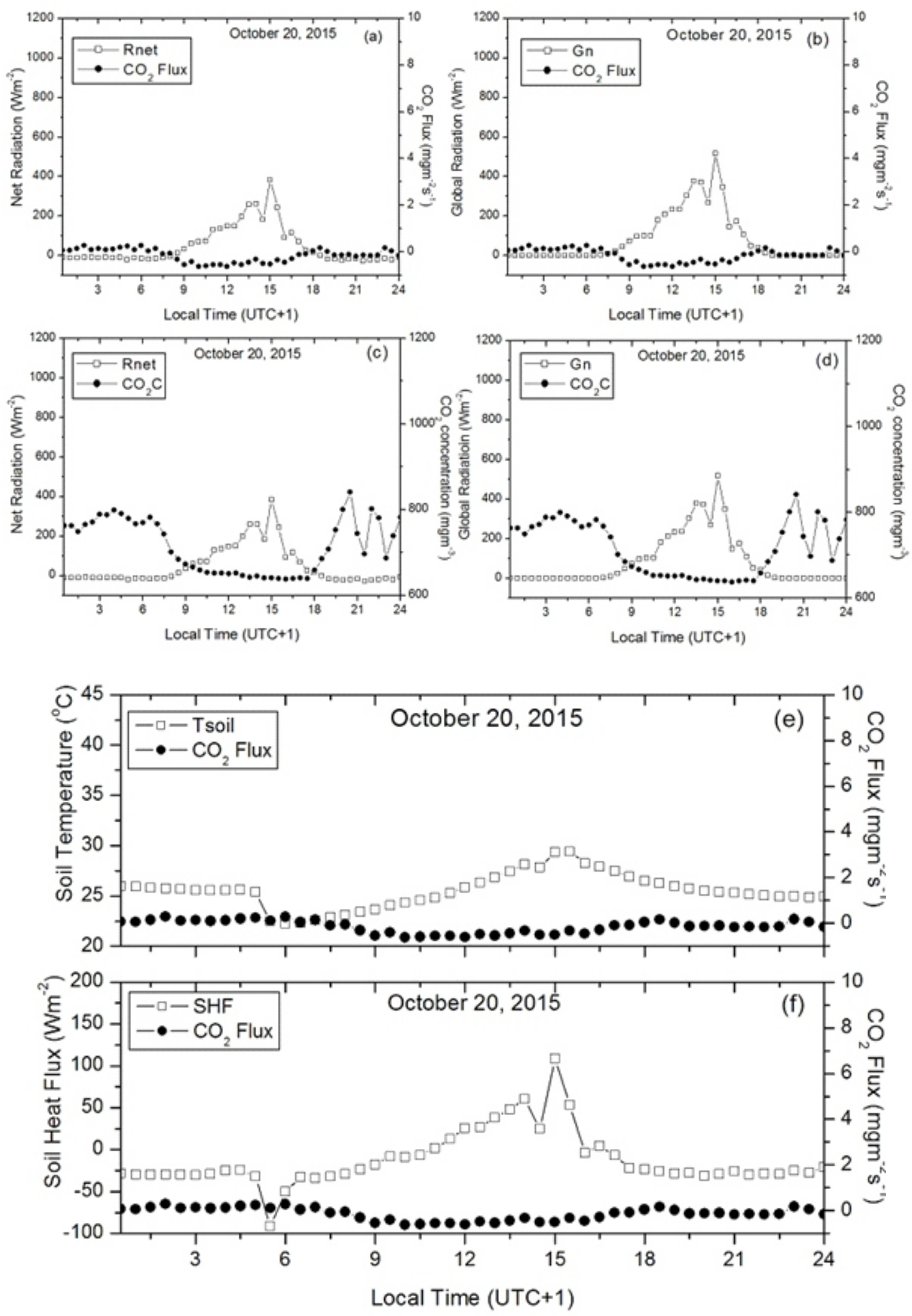

Figure 8: Diurnal Variation of $\mathrm{CO}_{2}$ Concentration and Fluxes and meteorological variables (Phase 2: October 2015). 


\section{Seasonal Variation of $\mathrm{CO}_{2}$ Fluxes}

Comparing results of the two seasonal transitions of planting i.e. dry-to-wet (March - June) and wetto-dry (August - November), the highest positive $\mathrm{CO}_{2}$ fluxes were observed between March and June which represented wet/rainy period when there were less sunlight and lower air temperature conditions. However, photosynthesis is expected to be very low and soil and plant respiration may explain the positive $\mathrm{CO}_{2}$ flux observed (see Figs. 3 and 4). The warm/dry period is considered to last from October, 2015 to February, 2016 but the measurement ended in November, 2015 being the month when the plant had withered. The period is a representative of the warm/dry conditions and there were much insolation and higher temperature conditions at the surface. Therefore, soil and plant respirations are expected to be lower and photosynthesis higher which then accounted for negative $\mathrm{CO}_{2}$ flux (see Figs. 5 and 6).

\section{CONCLUSION}

The study concluded that $\mathrm{CO}_{2}$ flux measured increased steadily from sunset until dawn from about $0.2 \mathrm{mgm}^{-2} \mathrm{~s}^{-1}$ around $1800 \mathrm{hrs}$ to reach maximum value, about $0.5 \mathrm{mgm}^{-2} \mathrm{~s}^{-1}$ at $0300 \mathrm{hr}$. Accordingly, $\mathrm{CO}_{2}$ flux was maximum during nighttime, irrespective of the growth stage of the plant and the fluxes decreased in values (magnitudes) as the plant graduated from one developmental stage to the next. Highest positive $\mathrm{CO}_{2}$ fluxes were observed in the wet/rainy period while lowest negative $\mathrm{CO}_{2}$ fluxes were observed in the warm/dry period. The major factor regulating $\mathrm{CO}_{2}$ flux availability over the plant, particularly in the daytime period is PAR.

\section{ACKNOWLEDGEMENTS}

The authors appreciate the support received from members of Atmospheric Physics Research Group (APRG) and technical staff at the department of Physics and Engineering Physics of Obafemi Awolowo University, Ile-Ife, Nigeria during the conduct of the study.

\section{REFERENCES}

Ayoola, M. A., Sunmonu, L. A., Bashiru, M. I. and Jegede, O. O. 2014. Measurements of net all-wave radiation at a tropical location, Ile-Ife, Nigeria, Atmósfera, 27, 305-315
Baldocchi, D., Falge, E., Gu, L. H., Olson, R., Hollinger, D., Running, S, et al., FLUXNET: 2001. A new tool to study the temporal and spatial variability of ecosystem-scale carbon dioxide, water vapor and energy flux densities. B. Am. Meteorol. Soc. 82, 2415-2434.

Campbell Scientific Instrument Manual. 2010. Campbell Scientific Instruments Manual, 815 West 1800 North, Logan, Utah. 84321 $-1784$.

Casso-Torralba, P., Vil`a-Guerau de Arellano, J., Bosveld, F., Soler,M. R., Vermeulen, A. and co-authors. 2008. Diurnal and verticalvariability of the sensible heat and carbon dioxide budgetsin the atmospheric surface layer. J. Geophys. Res. 113, doi:10.1029/2007JD009583

Dragomir, C. M., Klaassen, W.,Voiculescu, M.,Georgescu, L. P. and Sander van der Laan. 2011. Estimating Annual $\mathrm{CO}_{2}$ Flux for Lutjewad Station Using Three Different Gap-Filling Techniques. The Scientific World Journal, 2012. doi:10.1100/2012/842893.

EPA, 2015. Climate Change Indicators in the United States: Atmospheric Concentrations of Greenhouse Gases www.epa.gov/climatechange/indicators. $12 \mathrm{pp}$.

Foken, T. and Wichura, B. 1996. Tools for quality assessment of surface-based flux measurements. Agric. and For. Meteorol.= 78 (12), 83-105.

Gilmanov, T. G. Baker, J. M..Bernacchi, C. J., Billesbach, D. P., Burba, G. G., Castro, S., Chen, J., Eugster, W., Fischer, M. L., Gamon, J. A., Gebremedhin, M. T., Glenn, A. J., Griffi s, J., Hatfield, J. L., Heuer, M. W., Howard, T. M., Leclerc, M. Y., Loescher, H. W., Marloie, O., Meyers, T. P., Olioso, A., Phillips, R. L., Prueger, J. H., Skinner, R. H., Suyker, A. E., Tenuta, M. and Wylie, B. K. 2014. Productivity and Carbon Dioxide Exchange of Leguminous Crops: Estimates from Flux Tower Measurements. Agronomy Journal: Crop Ecology and Physiology, 106, 545-559.

IPCC, 2007. Global Atmospheric Concentrations 
of Greenhouse gases: carbon dioxide as a case study. IPCC Fourth Assessment Report on climate change. Cambridge, United Kingdom, Cambridge University Press.

Jegede, O. O., Fasheun, T. A., Adeyefa, Z. D. and Balogun, A. A. 1997. The effect of atmospheric stability on the surface-layer characteristics in a low-wind area of tropical West Africa.Boundary-Layer Meteorology. 85, 309-323.

Keeling, C. D., Piper, S. C., Bacastow, R. B., Wahlen, M., Whorf, T. P. and co-authors. 2005. Atmospheric $\mathrm{CO}_{2}$ and $\mathrm{CO}_{2}$ exchange with the terrestrial biosphere and oceans from 1978 to 2000: observations and carbon cycle implications. In: A History of Atmospheric $\mathrm{CO}_{2}$ and Its Effects on Plants, Animals, and Ecosystems. (eds. J. R. Ehleringer, T. E. Cerling and M. D. Dearing). Springer, New York, 83-113.

Loladze, I. 2002. Rising Atmospheric $\mathrm{CO}_{2}$ and Human Nutrition: Toward Globally Imbalanced Plant Stoichiometry? Trends in Ecology and Evolution. 442 - 461, doi: 10.1016/S0169-5347(02)02587-9. https://www.researchgate.net/publicatio $\mathrm{n} / 223483844$.

Neumann, M., Zhao, M.S., Kindermann, G. and Hasenauer, H. 2015. Comparing MODIS net primary production estimates with terrestrial national forest inventory data in Austria. Remote Sens. 7:3878-3906.
Phillips, O.L., Malh, Y., Higuchi, N., Laurance, W. F., Nunez, P. V., Vasquez, R.M., Lsurace, S. G., Ferreira, L. V., Stern, M., Brown, S. and Grace, J. 1998. Changes in the carbon of tropical forest: Evidence form long-term plots. Science, 282: 439-442.

Taub, D. R. 2010. Effects of rising atmospheric concentrations of carbon dioxide on plants. Nature Education Knowledge, 1, www.researchgate.net/publication/28451 5083.

Vanuytrecht, E., Raesa, D. and Patrick Willems, P. 2011. Considering sink strength to model crop production under elevated atmospheric $\mathrm{CO}_{2}$. Agricultural and Forest Meteorology, 151, 1753-1762.

Zhang, L., Sun, R., Xu, Z, Qiao, C. and Jiang, G. 2015. Diurnal and Seasonal Variations in Carbon Dioxide Exchange in Ecosystems in the Zhangye Oasis Area, Northwest China. , PLOS ONE, 10, e0130243. doi: 10.1371/journal.pone.0120660.

Zhao, L., Li, J., Xu, S., Zhou, H., Li, Y., Gu, S, et al. 2010 .Seasonal variations in carbon dioxide exchange in an alpine wetland meadow on the Qinghai-Tibetan Plateau. Biogeosciences. 7:1207-1221.

Ziska, L. H. 2008. Rising atmospheric Carbon dioxide and Carbon Biology. The Overlooked Paradigm. In Controversies in science and Technology, From Climate to Chromosomes. Eds. Kleinman, D. L., Cloud-Hansen, K. A. et al. (New Rochele, Liebert, Inc. 2008), 379- 400. 